\title{
Da linguística geral à poética do traduzir: a atividade de escuta na tradução
}

\author{
Daiane Neumann* \\ Antonella Romina Savia Vidales **
}

Resumo: Este artigo traça um percurso teórico da Linguística Geral, proposta por Ferdinand de Saussure, passando por Émile Benveniste, para chegar à Poética do Traduzir, como a concebeu Henri Meschonnic. O objetivo desse percurso é refletir acerca da discussão sobre a forma e o sentido na linguagem que se inicia no Curso de Linguística Geral, de Saussure, e é retomada nos Problemas de Linguística Geral I e II, de Benveniste, para chegar à discussão acerca do som e do sentido, trazida à baila por Meschonnic em sua Poética, a fim de propor a consideração da atividade de escuta da enunciação no traduzir.

Palavras-chave: Linguística Geral. Poética do Traduzir. Tradução.

Abstract: This article aims at establishing a theoretical framework of General Linguistics, by Ferdinand de Saussure, through Émile Benveniste's works reaching the Poetics of Translating, by Henri Meschonnic. Also, its aim is to consider the listening activity of the enunciation while translating, and, yet, reflect on the discussion concerning form and sense in language - which arises in Course in General Linguistics, by Saussure - and is reviewed in Problems in General Linguistics I and II, by Benveniste, reaching the discussion regarding sound and sense proposed by Meschonnic in his Poetics.

Keywords: General Linguistics. Poetics of Translating. Translation.

Resumen: Este artículo traza un camino teórico de la Lingüística General, propuesta por Ferdinand de Saussure, pasando por Émile Benveniste, para llegar a la Poética del traducir, concebida por Henri Meschonnic. El objetivo de este recorrido es reflexionar acerca de la discusión sobre la forma y el sentido en el lenguaje que comienza en el Curso de Lingüística General, de Saussure, y es retomada en los Problemas de Lingüística General Iy II, de Benveniste, para llegar a la discusión sobre el sonido y el sentido, planteada por Meschonnic en su Poética, para proponer la consideración de la actividad de escucha de la enunciación en la traducción. Palabras-clave: Lingüística General. Poética del Traducir. Traducción.

\footnotetext{
* Professora dos cursos de Letras e do Programa de Pós-Graduação em Letras da Universidade Federal de Pelotas (UFPel). http://orcid.org/oooo-0002-7363-0375 / E-mail: daiane neumann@hotmail.com

** Doutoranda no Programa de Pós-Graduação em Letras da Universidade Federal de Pelotas (UFPel). http://orcid.org/o000-0002-5210-6400 / E-mail: antonellasavia@hotmail.com
}

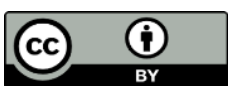




\section{Considerações iniciais}

A poética do traduzir, proposta por Meschonnic (2010), surge a partir das transformações sobre linguagem, língua e, principalmente, do advento do estudo do discurso, iniciados no século XX. Deixou-se, assim, de se observar a língua como signos independentes e passou-se a observar o discurso, ou seja, traduzir não é mais passar de uma língua para outra e, sim, traduzir um texto em sua globalidade, conforme proposto por Meschonnic em sua Poética. Não se pensa mais o ato de tradução na relação de língua a língua, e sim "[...] de texto a texto, ao contrário, trabalhando para mostrar a alteridade linguística, cultural, histórica, como uma especificidade e uma historicidade” (2010, p. XXIV).

Partindo das discussões e reflexões propostas pela poética do traduzir, este artigo tem por objetivo pensar sobre a forma e o sentido, o som e o sentido na linguagem, a fim de colocar em questão a escuta da enunciação no ato de tradução. Para fazê-lo, apresentaremos a reflexão proposta por Saussure, no Curso de Linguística Geral, ao discutir a relação entre forma e sentido no sistema da língua. Em seguida, trataremos da relação entre forma e sentido, no discurso, em reflexão sustentada por Émile Benveniste em seus Problemas de Linguística Geral I e II. Por fim, discutiremos sobre a relação entre forma e sentido, som e sentido na tradução, lançando mão da proposta de Meschonnic de que se deve traduzir o ritmo dos textos e das obras.

Pretendemos, dessa forma, levantar questionamentos e discussões que sejam pertinentes às reflexões acerca da língua, notadamente, no que tange a problemas que concernem o traduzir. Consideramos, ainda, que tais reflexões lançam luz ao estudo da língua e da literatura, já que os problemas de linguagem e/ou de língua com os quais se depara o tradutor são da mesma forma problemas pertinentes ao linguista e àquele que se dedica ao estudo da literatura.

A fim de iniciar a discussão aqui proposta, consideraremos a reflexão apresentada por Saussure, em seu Curso, acerca da relação que se estabelece entre forma e sentido. 


\section{A forma e o sentido na linguística geral de F. de Saussure}

O Curso de Linguística Geral (CLG) é o livro fundador daquilo que Meschonnic chama das transformações sobre a linguagem do início do século XX. Como parte dessas “transformações”, podemos destacar o fato de que Saussure propõe que a língua não é um objeto dado, mas construído, bem como a percebe tal qual um sistema de valores arbitrários que estabelece um funcionamento.

Saussure percebe que, em linguística, à diferença das demais ciências, o objeto de estudo não é dado, é construído a partir do ponto de vista pelo qual se observa a língua, “[...] em nenhuma parte se nos oferece integral o objeto da Linguística” (2012, p. 40). Os estudos linguísticos são construídos a partir do ponto de vista lançado sobre a língua.

Essa constatação e a importância dada a ela por Saussure permitem reatualizar as noções de realismo e nominalismo, ilusoriamente atribuídas à história do pensamento linguístico e à Idade Média, quando são, de fato, dados fundamentais da linguagem (MESCHONNIC, 2005). Com essa discussão, o linguista genebrino propõe que, "em matéria de linguagem, e da relação entre linguagem e pensamento, não há verdade, há somente pontos de vista”" (MESCHONNIC, 2005, p.14, tradução nossa).

A linguagem é definida, assim como constituída por “[...] um lado individual e um lado social, sendo impossível conceber um sem o outro" (SAUSSURE, 2012, p. 40). Apesar de Saussure ter operado com uma separação metodológica entre língua e fala para poder construir o objeto de estudo da linguística, a saber, a língua, ambos os conceitos estão tecidos ao longo do $C L G$, apontando para a sua indissociabilidade: “[...] a fala faz evoluir a língua [...]. Existe, pois, interdependência da língua e da fala [...]. Tudo isso, porém, não impede que sejam duas coisas absolutamente distintas" (2012, p. 51). O linguista se propõe a investigar a língua, uma vez que diferentemente da fala, é passível de ser estudada separadamente.

\footnotetext{
${ }^{1}$ No original: "en matière de langage, et de rapports entre le langage et la pensée, il n'y a pas de vérité, il n'y a que des points de vue".
} 
A língua é, então, definida a partir da linguagem, como "[...] um produto social da faculdade da linguagem e um conjunto de convenções necessárias, adotadas pelo corpo social para permitir o exercício dessa faculdade nos indivíduos" (SAUSSURE, 2012, p. 41).

A língua é constituída por um sistema de signos, que estabelecem relações entre os elementos do sistema e constroem seus valores a partir dessas relações. Tal consideração se faz importante para compreender como articula-se a relação entre forma e sentido no pensamento saussuriano.

Para estudar esse sistema, o linguista propõe o que denomina "Semiologia", “[...] uma ciência que estude a vida dos signos no seio da vida social. [...] Ela nos ensinará em que consistem os signos, que leis os regem" (SAUSSURE, 2012, p. 47). A linguística faria parte dessa ciência, sendo dever do linguista estudar a língua como sistema de signos.

Lido a partir do primado do sistema, percebe-se que o CLG propõe que

[...] é uma grande ilusão considerar um termo simplesmente como a união de certo som com um certo conceito. Defini-lo assim seria isolá-lo do sistema do qual faz parte; seria acreditar que é possível começar pelos termos e construir o sistema fazendo a soma deles, quando, pelo contrário, cumpre partir da totalidade solidária para obter, por análise, os elementos que encerra (SAUSSURE, 2012, p. 160).

A partir disso, considera-se, portanto, que a própria relação entre significante e significado, entre forma e sentido, é dada via relações estabelecidas no sistema.

O valor do signo é, dessa forma, definido dentro do sistema da língua por oposição, ou seja, "[...] na língua cada termo tem seu valor pela oposição aos outros termos" (SAUSSURE, 2012, p. 130). Saussure ilustra a noção de valor através da metáfora do jogo de xadrez, em que cada peça tem seu valor estabelecido dentro do jogo e com relação às demais peças. Na língua, cada signo tem seu valor estabelecido na relação com os demais signos.

O valor de determinado signo é estabelecido, portanto, pela presença dos outros signos. Os valores podem ser dessemelhantes ou semelhantes, “[...] uma palavra pode ser trocada por algo dessemelhante: uma ideia; além disso, pode ser comparada com algo da mesma natureza: uma palavra" (SAUSSURE, 2012, p. 162). Dessa forma, "se as palavras estivessem encarregadas de representar os conceitos dados de antemão, cada uma delas 
teria, de uma língua para outra, correspondentes exatos para o sentido; mas não ocorre assim" (SAUSSURE, 2012, p. 163). O Curso aborda, a título de exemplificação, as palavras carneiro, em português, e mouton e sheep, em francês e inglês respectivamente, as quais não teriam correspondentes exatos para o sentido de uma língua para a outra, ou seja, constituiriam diferentes valores (SAUSSURE, 2012).

O valor do signo linguístico é determinado na relação dentro do sistema. Cada signo ganha valor na relação com os demais signos da língua. A exemplo disso, tem-se os sinônimos cujo valor é dado pela oposição entre eles, “[...] recear, temer, ter medo só têm valor próprio pela oposição; se recear não existisse, todo seu conteúdo iria para os seus concorrentes" (2012, p. 163).

A passagem "sua característica mais exata é ser o que os outros não são" (SAUSSURE, 2012, p. 164) resume a noção de valor, pois é nessa relação entre os signos de uma mesma língua ou de línguas diferentes que o valor de cada signo linguístico é construído. As relações então são estabelecidas dentro dos eixos sintagmático e associativo. Do eixo sintagmático fazem parte as "[...] relações baseadas no caráter linear da língua, que exclui a possibilidade de pronunciar dois elementos ao mesmo tempo" (SAUSSURE, 2012, p. 171). Cada termo da palavra ganha valor em relação com os demais termos. No eixo associativo, tem-se a formação de grupos de palavras que ficam na memória: "A relação sintagmática existe in praesentia; repousa em dois ou mais termos igualmente presentes numa série efetiva. Ao contrário, a relação associativa une termos in absentia numa série mnemônica virtual” (SAUSSURE, 2012, p. 172).

O pensamento de que a língua funciona em um sistema de signos, em que o todo constitui o valor das partes só é possível na linguística saussuriana, a partir do princípio da arbitrariedade. O linguista afirma, assim, que a língua não serve para dar nome às coisas, na medida em que não existem ideias pré-dispostas, "o signo linguístico une não uma coisa e uma palavra, mas um conceito e uma imagem acústica” (SAUSSURE, 2012, p. 106); “o signo linguístico é, pois, uma entidade psíquica de duas faces” (SAUSSURE, 2012, p. 106). O signo é formado por um significado (conceito) e um significante (imagem acústica). Na relação entre os dois termos, encontramos, novamente, o valor.

Percebe-se, pois, que a noção de valor e de arbitrário constituem a discussão acerca da forma e do sentido no $C L G$, na medida em que a relação entre significante e 
significado constrói o valor do signo e, da mesma forma, é construída mediante o valor de um signo em relação aos outros do sistema. Ademais, o laço que liga os dois elementos do signo é arbitrário.

Assim, o próprio conceito de signo linguístico é construído a partir da indissociabilidade entre forma e sentido. A união entre significante e significado é denominada, por Saussure, arbitrária. A arbitrariedade é o "[...] laço natural que une o significante ao significado" (SAUSSURE, 2012, p. 108), ou seja, a união do significante com o significado, que juntos formam o signo linguístico, ocorre de forma arbitrária. A arbitrariedade é, portanto, um fator determinante na existência de línguas e línguas diferentes, uma vez que não há correspondentes idênticos de uma língua para outra.

Como pontua Normand (2009), o signo tal como foi apresentado por Saussure não pode ser concebido conforme a definição clássica de representante de uma ideia, menos ainda de uma coisa. Assim, "todo locutor, em dado momento, fala do mundo ou compreende o que se diz dele pela intermediação de sua língua” (NORMAND, 2009, p. 63)

A discussão sobre a forma e o sentido na linguagem está presente também nos Écrits de linguistique générale, na primeira parte, denominada "Sobre a essência dupla da linguagem (Acervo BPU 1996)", em que Saussure discorre acerca da relação entre forma e sentido. Meschonnic (2005) nota que, no prefácio da parte referida dos Écrits, afirma-se que "é errado (e impraticável) opor a forma e o sentido. O que é certo, em troca, é opor a figura vocal, de um lado, e a forma-sentido de outro" (SAUSSURE, 2004, p. 21).

A indissociabilidade entre forma e sentido está, portanto, no centro da discussão concernente à observação da língua enquanto um sistema de valores arbitrários, na medida em que se as unidades são constituídas pelo todo, e não o contrário, então, os dois elementos do signo são dados juntos, "estão intimamente unidos e um reclama o outro" (SAUSSURE, 2012, p. 107)

A discussão sobre esse valor linguístico cuja construção se dá a partir da consideração da noção de arbitrário e de sistema e que são suscitados e significados via discurso, é muito profícua na obra de Benveniste sobre a qual discutiremos abaixo. 


\section{A forma e o sentido na linguística geral de É. Benveniste}

Benveniste, continuador de Saussure, propõe o estudo do discurso em conjunto com o da língua. O linguista centra sua discussão na questão da subjetividade na linguagem. Nas obras Problemas de Linguística Geral I e II (PLG I e PLG II), o autor discorre acerca da linguagem, considerando-a sob a perspectiva do discurso. A linguagem constrói a cultura, o pensamento e o homem. Benveniste explica que o uso da palavra instrumento para fazer referência à linguagem não deve ser confundida com o uso da palavra instrumento que remete àquilo que é fabricado pelo homem; “a picareta, a flecha, a roda não estão na natureza" (BENVENISTE, 2005, p. 285), ou seja, a linguagem é natural ao homem que não a fabricou, ambos nascem juntos; "não atingimos nunca o homem separado da linguagem e não o vemos nunca inventando-a" (BENVENISTE, 2005, p. 285).

Quando discute acerca da subjetividade, o autor está abordando a “[...] capacidade do locutor para se propor como 'sujeito"' (BENVENISTE, 2005, p. 286), isso quer dizer que é fazendo uso da linguagem que o homem se define na sociedade. Dentro da reflexão sobre a subjetividade é que o linguista propõe as marcas enunciativas. É na relação entre o eu-tu-língua que o homem se constitui como sujeito. Dessa forma, não se pode pensar o homem e a sociedade de forma dissociada, eles nascem juntos, e isso torna possível o estudo da subjetividade na linguagem.

A subjetividade proposta por Benveniste abarca a importância da linguagem para a sociedade, a cultura e o homem, "é na linguagem e pela linguagem que o homem se constitui como sujeito" (2005, p. 286), é necessário que haja linguagem para que o sujeito se institua na realidade e faça parte da sociedade.

Para o autor, a linguagem significa e possui forma e sentido. $\mathrm{O}$ discurso cria o sentido dos signos no sistema da língua e, assim, as palavras ganham sentido no discurso, "é no uso da língua que um signo tem existência; o que não é usado não é signo; e fora do uso o signo não existe" (BENVENISTE, 2006, p. 227). Partindo do proposto por Saussure, Benveniste apresenta o que denominou domínio semântico, que nos “[...] 
introduz no domínio da língua em emprego e em ação; vemos desta vez na língua sua função mediadora entre o homem e o homem, entre o homem e o mundo [...] organizando a vida dos homens" (2006, p. 229). O semântico leva em consideração a relação entre a língua, a cultura e a sociedade, observando a frase, não mais apenas o signo. "A semiótica se caracteriza como uma propriedade da língua; a semântica resulta de uma atividade do locutor que coloca a língua em ação” (BENVENISTE, 2006, p. 230).

Benveniste, então, propõe no semântico o estudo da língua em ação. Deixa-se, agora, de considerar apenas a língua como sistema de signos e se passa a considerar a frase como produtora de discurso, através do que o locutor diz no ato de enunciação. É nessa relação entre o sentido e a forma, entre a sociedade, a cultura e o homem que Benveniste explica sua noção de significação. É pela linguagem que se torna possível o viver, a cultura, o homem, a sociedade, "ela não diz nem oculta, mas ela significa” (20o6, p. 234).

Benveniste destaca que a língua possui forma e sentido e que esses elementos estão interligados em toda a extensão da língua. O linguista explica: "a forma de uma unidade linguística define-se como a sua capacidade de dissociar-se em constituintes de nível inferior. O sentido de uma unidade linguística define-se como a sua capacidade de integrar uma unidade de nível superior" (2005, p. 136). Dessa maneira, a forma e o sentido não podem ser dissociados, devem ser analisados em conjunto no funcionamento da língua.

Benveniste apresenta três noções de sentido, no texto "Os níveis de análise linguística", sendo a terceira a que ele propõe como fundamental para sua teorização. A primeira noção de sentido considera o legado de Saussure e propõe que o sentido seja estabelecido no sistema, na relação entre os signos linguísticos, "forma e sentido aparecem assim como propriedades conjuntas, dadas necessária e simultaneamente, inseparáveis no funcionamento da língua” (BENVENISTE, 2005, p. 136). A segunda noção de sentido é explicada quando uma unidade integra a unidade de nível superior, por exemplo o fonema integra a palavra, "esse 'sentido' é implícito, inerente ao sistema linguístico e às suas partes" (BENVENISTE, 2005, p. 137). A terceira noção de sentido é aquela que diz respeito ao referendum, ou seja, o uso da língua é considerado na construção do sentido. Aqui Benveniste inclui a frase como último nível de estudo, "a 
frase [...] é a própria vida da linguagem em ação. Concluímos que se deixa com a frase o domínio da língua como sistema de signos e se entra num outro universo, o da língua como instrumento de comunicação, cuja expressão é o discurso” (2005, p. 139).

A frase é, pois, “[...] uma unidade completa, que traz ao mesmo tempo sentido e referência: sentido porque é informada de significação, e referência porque se refere a uma determinada situação" (BENVENISTE, 2005, p. 140). Deve-se, então, partir do todo do discurso (as frases), para buscar as unidades da língua. É a frase que constrói a semântica proposta por Benveniste.

A linguagem para o autor é carregada de significação, sendo a língua uma propriedade de significado. É na linguagem que encontramos as unidades de nível inferior até o nível superior. Ao decompormos a língua,

[...] suas unidades se agrupam para formar novas unidades, e estas por sua vez poderão formar outras ainda, de um nível cada vez superior. Ora, a unidade particular que é o signo tem por critério um limite inferior: este limite é o da significação; não podemos descer abaixo do signo sem perder a significação. (BENVENISTE, 2006, p. 225).

Benveniste relaciona a forma e o sentido, em um primeiro momento, ao significante e ao significado do signo: "O significante [...] é a forma sonora que condiciona e determina o significado” (2006, p. 225). Assim, cada língua possui suas características próprias, seu sistema. "Cada língua, em sua organização, está sujeita a análises semelhantes e se obterá assim esquemas que ilustrarão a própria estrutura de cada idioma” (BENVENISTE, 2006, p. 226). O significado está relacionado ao uso do signo na comunidade linguística, "no plano do significado, o critério é: isto significa ou não? Significar é ter um sentido, nada mais" (2006, p. 227). O signo linguístico ganha valor ao ser utilizado na fala.

Benveniste questiona então o papel da frase na linguagem. É por meio dela que nos comunicamos. Assim, explica que a forma e o sentido na língua podem ser entendidos do ponto de vista semiótico, proposto por Saussure, ou do ponto de vista semântico, proposto por ele. "A noção de semântica nos introduz no domínio da língua em emprego e em ação; vemos desta vez na língua sua função mediadora entre o homem e o homem, entre o homem e o mundo" (BENVENISTE, 2006, p. 229). 
A partir do ponto de vista semântico, “[...] o 'sentido’ da frase está na totalidade da ideia percebida por uma compreensão global; a 'forma' se obtém pela dissociação analítica do enunciado processada até nas unidades semânticas, as palavras" (BENVENISTE, 2006, p. 232). Podemos, então, compreender que, dentro do semiótico, a forma está ligada ao significante, e o sentido ao significado. No semântico, a forma e o sentido estão inter-relacionados dentro da frase e sua relação se estabelece a partir do processo de sintagmatização e semantização.

\section{A forma e o sentido na poética do discurso: em busca da escuta do ritmo na tradução}

Discutindo de forma mais contundente a respeito da questão por nós aqui tratada, Meschonnic (2010), ao filiar-se às transformações sobre a língua e a linguagem no século XX, propostas por Saussure e Benveniste, parte da indissociabilidade entre forma e sentido e denuncia a separação tradicional entre o sentido e o estilo, entre o sentido e a forma, afirmando que uma boa tradução deve fazer algo e não somente dizer. Para tanto, é preciso que se considere o sentido e o estilo, o sentido e a forma, como indissociáveis.

Essa concepção tão difundida estaria pautada em uma oposição entre os descobridores de fontes e os alvejadores. Os primeiros buscariam a língua de partida, na tentativa de decalcar, enquanto os alvejadores olhariam adiante, de forma realista, em direção à língua de chegada, na tentativa de preservar o essencial, ou seja, o sentido. Os descobridores de fontes estariam ávidos pela forma.

Essa separação observada nos estudos da tradução tem suas raízes naquela tão presente nos estudos da linguagem, que considera a divisão do signo, como uma aliança de um significante, fônico ou gráfico, a forma, e de um significado, o sentido. Meschonnic (2010) considera que a tradução, segundo o comando do signo, "induz a uma esquizofrenia do traduzir" (p. XXX), pois, em realidade, o que se busca traduzir é o sentido, que, em verdade, nunca está só. Nessa concepção tão recorrente, a noção de 
forma figura como resíduo daquilo que se acredita ser o sentido, que toma como unidade a palavra.

Ao considerar a forma e o sentido enquanto indissociáveis, Meschonnic (2010) propõe que a unidade seja o discurso, o sistema de discurso. Para a poética, "a unidade é da ordem do contínuo - pelo ritmo, a prosódia - e não mais da ordem do descontínuo, onde a distinção mesmo entre língua de partida e língua de chegada volta a reunir a oposição entre significante e significado” (MESCHONNIC, 2010, p. XXXI).

O teórico da linguagem e tradutor denuncia o que chamou de uma "surdez", que se deve a duas atitudes, a primeira diz respeito à uma redução da linguagem às unidades da língua; a segunda refere-se à surdez ao discurso, como atividade dos sujeitos. A proposta é de que o tradutor se coloque em uma situação de escuta do texto a traduzir. Assim, a tradução não é mais do enunciado, mas da enunciação.

A proposta de que se deva traduzir o sistema de discurso leva a retomar Saussure, pois o sentido de sistema é resgatado por Meschonnic, considerando-o

\footnotetext{
um conjunto de diferenciais internos, radicalmente históricos, à diferença da estrutura estruturalista e semiótica, que trata como pares de exclusão mútua os pares de implicação recíproca, em Saussure, entre língua e palavra, sincronia e diacronia (aos dois, o conjunto, a história, estado e mudança) sintagmática e associativa. Não paradigmática. (MESCHONNIC, 2010, p. XXXII).
}

Nesse sentido, Meschonnic (2010) propõe que a poética seja saussuriana, mas antiestruturalista. Dessa forma, sistema, valor, funcionamento e o radicalmente arbitrário, radicalmente histórico, são diretamente atualizados por Meschonnic para pensar o discurso. A crítica das "subdivisões tradicionais" por Saussure - léxico, morfologia, sintaxe - foi lida como condição necessária para a elaboração de um pensamento do discurso, de uma poética do contínuo em Meschonnic (2010).

Considerando ainda a noção de discurso e de subjetividade em Benveniste, Meschonnic propõe que o traduzir passe por uma escuta do contínuo, que seja uma subjetivação por uma subjetivação. Subjetivação que, para o teórico da linguagem, pertence a uma prática e a um pensamento do contínuo, contínuo rítmico, prosódico semântico; contínuo da linguagem ao seu sujeito; contínuo da língua à literatura, do discurso à cultura, da linguagem à história. 
Essa separação entre forma e sentido gera, segundo o teórico, uma situação em que se concebem significantes diferentes para um significado: muitas palavras para uma mesma palavra (não-concordâncias), uma mesma palavra para muitas diferentes (anticoncordâncias). É preciso, portanto, passar do "sentido ao modo de significar, do descontínuo do signo ao contínuo do ritmo e da prosódia como semântica não lexical” (MESCHONNIC, 2010, p. XXXV).

Dessa forma, se o discurso é atividade, conforme o concebeu Humboldt, de um homem em vias de falar, pois "historicamente nós só temos a ver com um homem em vias de falar" (HUMBOLDT, 1974, p. 246 apud MESCHONNIC, 2010, p. XX), há uma implicação da inscrição gramatical daquele que diz eu no seu discurso, de acordo com o que propôs Benveniste. Para Meschonnic, essa enunciação não saberia se limitar a ser lógica ou ideológica, pois carrega consigo uma atividade do sujeito, que passa de sujeito da enunciação a uma subjetivação do contínuo, no contínuo do discurso, rítmico e prosódico.

A organização dessa subjetivação no discurso transforma os valores da língua em valores do discurso, isso seria uma escrita, o que é preciso traduzir. Transforma-se, assim, o pensamento da linguagem, não se pensa mais a partir das categorias da língua (léxico, morfologia, sintaxe), mas a partir do discurso, do sujeito ativo, dialogante, "inscrito prosaicamente ritmicamente na linguagem, com a sua fisicalidade" (MESCHONNIC, 2010, p. XXI).

O pensamento poético propõe que a tradução seja uma maneira particular pela qual um sujeito transforma, ao inventar-se, ao inventar os modos de significar, de sentir, de pensar, de compreender, de ler, de ver e de viver na linguagem. Haveria, portanto, um modo de ação sobre a linguagem.

Essa invenção dos modos de significar, do sujeito, "é ferida imediatamente pelo impensado da relação interna (no sentido do que Humboldt chamava interação, Wechselwirkung) entre língua, cultura, literatura” (MESCHONNIC, 2010, p. XXXVII). Por isso, é preciso "traduzir não o que dizem as palavras, mas o que elas constroem" (MESCHONNIC, 2010, p. LXII).

Os problemas do traduzir, nessa perspectiva teórica, são também os problemas da teoria geral da linguagem, já que é possível observá-los a partir de uma crítica do 
signo, possível e necessária, que surge através de um pensamento do conjunto da linguagem e da literatura. Dessa forma, pode-se perceber que os problemas do traduzir põem a nu os efeitos do signo. A tradução se constitui como uma poética experimental e "um lugar de observação único para a teoria da linguagem" (MESCHONNIC, 2010, p. LXIII).

Para Meschonnic, a força de uma tradução bem-sucedida é que "ela é uma poética para uma poética" (2010, p. LXIV), não de sentido pelo sentido, nem de palavra pela palavra, mas por aquilo que faz de um ato de linguagem um ato de literatura. A poética é, assim, "um convite ao tradutor para inscrever-se no texto traduzido" (2010, p. XIII).

A equivalência não se dá mais de língua a língua, em busca de um apagamento das diferenças linguísticas, culturais, históricas, mas de texto a texto, trabalhando para mostrar, ao contrário, a alteridade linguística, cultural, histórica, como uma especificidade e uma historicidade.

\section{Considerações finais}

A reflexão aqui proposta colocou em evidência uma temática pouco discutida, mas bastante pertinente para os estudos da tradução, a questão da relação entre forma e sentido. É através de tal problematização que se pode compreender, discutir e aprofundar o que propõe a poética de Meschonnic, ao afirmar que é preciso "Traduzir o que as palavras não dizem, mas o que elas fazem”2 (MESCHONNIC, 1995).

Para a poética, traduzir o que as palavras dizem coloca o tradutor diante do sentido, da tradução dos sentidos. Traduzir o que as palavras fazem significa, por outro lado, considerar a forma e o sentido enquanto indissociáveis, dessa forma, traduz-se também o efeito, o ritmo, a prosódia.

Para desenvolver tal discussão, resgatamos a reflexão de Saussure, no seu Curso, que propõe que a língua seja um sistema de signos arbitrários e, para isso, ao considerar

\footnotetext{
${ }^{2}$ Tradução nossa. No original: “Traduire ce que les mots ne disent pas, mais ce qu'ils font”. 
o signo como a união de um significante e um significado, inicia o debate sobre a indissociabilidade entre a forma e o sentido na língua. Em seguida, a fim de considerar a indissociabilidade entre forma e sentido no discurso, buscamos apoio em Benveniste, que resgata a reflexão saussuriana, no que denominou de semiótico, mas também a amplia, na consideração do domínio da frase, do semântico.

Para finalizar o debate, focamos na proposta da poética de Meschonnic, para quem a indissociabilidade entre forma e sentido é vital no traduzir. Meschonnic, continuador do pensamento saussuriano e benvenistiano, atenta para a importância de se considerar o ritmo, a entonação e a prosódia, na tradução.

O debate aqui proposto é de relevância, portanto, tanto para quem se dedica à tradução, quanto para aqueles que se situam no terreno dos estudos da linguagem e dos estudos literários, pois atentar para o modo de significar, de ser, de viver na linguagem interessa a todos aqueles cujo objeto de trabalho seja a linguagem.

\section{Referências}

BENVENISTE, É. Problemas de Linguística Geral I. Tradução de Maria da Gloria Novak e Maria Luisa Neri. $5^{\mathrm{a}}$ ed. Campinas: Pontes Editora, 2005.

BENVENISTE, É. Problemas de Linguística Geral II. Tradução de Eduardo Guimarães. $2^{\underline{a}}$ ed. Campinas: Pontes Editora, 2006.

MESCHONNIC, H. Traduire ce que les mots ne disent pas, mais ce qu'ils font. Meta Journal des traducteurs, Montréal, v. 40, n. 3., p. 514-517, 1995.

MESCHONNIC, H. Saussure ou la poétique interrompue. In: CHISS, J-L.; DESSONS, G. Langages, 39e année, n. 159, 2005.

MESCHONNIC, H. Poética do traduzir. Tradução de Jerusa Pires Ferreira e Suely Fenerich. São Paulo: Perspectiva, 2010.

NORMAND, C. Saussure. Tradução de Ana de Alencar e Marcelo Diniz. São Paulo: Estação Liberdade, 2009. 
SAUSSURE, F. de. Escritos de Linguística Geral. Organizados e editados por Simon Bouquet e Rudolf Engler, com colaboração de Antoinette Weil. Tradução de Carlos Augusto Leuba Salum e Ana Lucia Franco. São Paulo: Cultrix, 2004.

SAUSSURE, F. de. Curso de Linguística Geral. Tradução de Antônio Chelini, José Paulo Paes e Izodoro Blikstein. 28a ed. São Paulo: Cultrix, 2012.

Recebido em 13/04/2021. Aprovado em 24/11/2021. 